\title{
CONCEITUAÇÃO DA EDUCAÇÃO EM SAÚDE E SUAS IMPLICAÇÕES NAS PRÁTICAS ESCOLARES
}

\section{CONCEPTS OF HEALTH EDUCATION AND IMPLICATIONS IN SCHOOL PRACTICE}

\author{
Julio Cesar Bresolin Marinho', João Alberto da Silva² \\ ${ }^{1}$ Professor da Universidade Federal do Pampa - UNIPAMPA, Campus Uruguaiana; Membro do Núcleo \\ de Estudos em Epistemologia e Educação em Ciências - NUEPEC (CNPq/FURG); \\ marinhojcb@gmail.com \\ 2 Professor da Universidade Federal do Rio Grande - FURG; Líder do Núcleo de Estudos em \\ Epistemologia e Educação em Ciências - NUEPEC (CNPq/FURG); joaosilva @ furg.br
}

\section{RESUMO}

O presente artigo procura problematizar três pontos: diferenciar o entendimento de educação em saúde de outras designações (saúde escolar, saúde do escolar, ensino de saúde, educação para a saúde e promoção da saúde); traçar um apanhado histórico sobre a forma de estruturação da educação em saúde na escola brasileira; compreender as possibilidades e barreiras encontradas na concretização da educação em saúde na escola. As problematizações foram construídas por meio de uma pesquisa bibliográfica decorrente de investigações anteriores (livros, artigos, teses, entre outras fontes). Evidenciamos que por ter um caráter multifacetado, o conceito de educação em saúde necessita ser problematizado, para buscarmos compreensões dos fenômenos desse campo de estudo. Observamos que desde a inserção da saúde nas escolas, é marcante a mudança comportamental. Analisando as potencialidades e barreiras para a concretização da educação em saúde, foi possível evidenciar a importância do trabalho com a temática, pelo significado que exprimem aos alunos.

Palavras-chave: educação em saúde, escola, práticas de ensino.

\begin{abstract}
This paper aims to discuss three points: (i) differentiating the understanding of health education from other designations (school health, student health, health teaching, education for health, and health promotion); (ii) drawing a historical overview on how health education is structured in Brazilian schools; and (iii) understanding opportunities and barriers encountered in implementing health education in school. The questioning was built through a literature arising from previous research (books, articles, theses/dissertations, among other sources). Because of its multifaceted character, the concept of health education has to be questioned in order to seek an understanding of the phenomena of this field of study. Since the inclusion of health in schools, a remarkable behavioral change is found. Analyzing the strengths and barriers to the implementation of health education made possible to demonstrate the importance of working with the theme for the meaning expressed to students.
\end{abstract}

Keywords: health education, school, teaching practices. 


\section{Introdução}

Em nossos estudos estamos trabalhando com a ideia da educação em saúde, mas esta expressão pode ter variados entendimentos, em virtude do campo de estudos da educação em saúde, possuir um caráter multifacetado. Por essa característica, é possível que imperem variados entendimentos sobre tal expressão - educação em saúde.

A intencionalidade deste artigo reside em três pontos centrais:

- diferenciar o nosso entendimento de educação em saúde de outras designações, tais como: saúde escolar, saúde do escolar, ensino de saúde, educação para a saúde e promoção da saúde;

- traçar um apanhado histórico sobre a forma de estruturação da educação em saúde na escola brasileira, apontando desde implementação da saúde nas escolas através da Lei 5.692 de 1971 (as ações de saúde eram estabelecidas por meio dos programas de saúde nas escolas de $1^{\circ}$ e $2^{\circ}$ graus, com o objetivo de estimular o conhecimento e a prática da saúde básica e da higiene), até o surgimento do programa saúde na escola (PSE), instituído pelo Decreto 6.286, de 5 de dezembro de 2007;

- compreender as possibilidades e barreiras encontradas para a concretização da educação em saúde na escola.

\section{Esclarecendo conceitos}

Pelo artigo primeiro da LDB (BRASIL, 1996), podemos entender que a educação "abrange os processos formativos que se desenvolvem na vida familiar, na convivência humana, no trabalho, nas instituições de ensino e pesquisa, nos movimentos sociais e organizações da sociedade civil e nas manifestações culturais". Nosso entendimento de saúde advém da definição da Organização Mundial da Saúde (OMS, 1946), que concebe a saúde não apenas como a ausência de doença no organismo, mas como a situação de perfeito bem-estar físico, mental e social do sujeito. Compreendendo o sentido amplo de educação e de saúde, qual o entendimento oriundo destas palavras quando são unidas pela preposição em, e originam a expressão educação em saúde?

Cardoso de Melo (1981) apresenta-nos que a educação em saúde emerge nos anos 50, devendo a saúde/doença ser compreendida na sua multicausalidade. Schall e Struchiner $(1999$, p. 4) apresentam a educação em saúde como sendo 
um campo multifacetado, para o qual convergem diversas concepções, das áreas tanto da educação, quanto da saúde, as quais espelham diferentes compreensões do mundo, demarcadas por distintas posições políticofilosóficas sobre o homem e a sociedade.

Por esta concepção a educação em saúde se constitui pela fusão de aspectos oriundos do campo educacional e da saúde, constituindo assim um campo de várias faces. O campo da educação em saúde, possuindo este caráter multifacetado, permite que imperem variados entendimentos sobre tal expressão. A concepção utilizada por nós, neste artigo, aproxima-se muito da ideia de Mohr (2002), a qual concebe a educação em saúde como consistindo nas atividades que compõem o currículo escolar, que apresentam uma intenção de caráter pedagógico ${ }^{1}$, a qual contenha relação com o ensino e aprendizagem de assuntos ou temas correlatos com a saúde. Essa autora ainda visualiza as propostas curriculares, projetos pedagógicos da escola ou planos de ensino dos professores como um ponto de relação, no qual é possível perceber esta intencionalidade pedagógica.

Indo além dos diversos entendimentos da expressão educação em saúde, outras denotações são cabíveis de diferenciação, como é o caso de saúde escolar, saúde do escolar, ensino de saúde, educação para a saúde e promoção da saúde. Conceição (1994, p. 11) compreende a expressão saúde escolar como algo mal definido, pouco conhecido e conceitua como "o conjunto de ações destinadas a promover, proteger e recuperar a saúde das coletividades integrantes do sistema educacional". Na visão de Lima (1985, p. 151), "a saúde escolar é um movimento amplo que estende suas ações a todos os aspectos da vida escolar, refletindo uma ânsia de controle e medicalização de toda a sociedade". Em relação à saúde do escolar, Sucupira e Zuccolotto (1994) apresentam vários pontos que se entrelaçam com a concepção de saúde escolar, ou seja, ações de saúde voltadas aos indivíduos que frequentam as escolas. Esses autores visualizam a origem desses programas como consistindo na preocupação com a questão do aprendizado, vinculando-o a uma condição prévia de bom estado de saúde, e mantêm o seu foco geralmente nas atividades de saúde bucal e saúde ocular. Pelas definições de saúde escolar e saúde do escolar, podemos perceber que, diferentemente da educação em saúde (que em nossa concepção prioriza um ato educacional), essas outras duas

\footnotetext{
${ }^{1}$ A autora enfatiza o caráter pedagógico, pelo fato de caracterizar como educação em saúde as atividades que sejam planejadas e organizadas com a finalidade de ensinar algo a alguém.
} 
práticas possuem um caráter de medicalização, que destoa do caráter educativo da educação em saúde. Desta forma, a saúde escolar, assim como a saúde do escolar vão ao encontro de um ato médico, ou seja, prestam assistência médica aos alunos integrantes do sistema educacional, ou aquelas crianças e adolescentes que se encontram em idade escolar.

Conceição (1994) divide a saúde escolar em quatro partes, sendo uma dessas o ensino de saúde que, para o autor, inclui o conjunto de conteúdos curriculares que serão formalmente desenvolvidos em sala de aula pelo professor. Essa concepção em um primeiro plano pode parecer se aproximar ou coexistir com nossa ideia de educação em saúde, pois aparenta denotar uma intencionalidade pedagógica. No entanto, ela acaba diferenciando-se, pois, no ensino de saúde, o trabalho é desenvolvido formalmente no espaço da sala de aula. Em nossa visão de educação em saúde, as atividades sistematizadas sobre a temática podem ocorrer em variados espaços, não necessitando de sua restrição às quatro paredes de uma sala de aula. Mohr (2002) nos disponibiliza alguns exemplos para podermos diferenciar estes pontos que levantamos em relação ao ensino e à educação em saúde. Para ela, atividades de educação em saúde são também as decorrentes de explicações proferidas por um engenheiro aos alunos durante visita a uma estação de tratamento de esgoto, ou também, quando o professor incumbe os alunos de realizar um levantamento, através de entrevistas, que vise analisar os hábitos alimentares da comunidade. Outro ponto divergente entre ensino e educação em saúde consiste no fato de o ensino de saúde ser compreendido basicamente como o ensino de conceitos e definiçõos. Por exemplo, em uma perspectiva de ensino de saúde, em uma aula sobre a doença de chagas, seria descrito que ela é causada pelo protozoário Tripanosoma cruzi, é transmitida, principalmente, por um inseto da subfamília Triatominae, conhecido popularmente como barbeiro. Talvez também fossem abordados os sintomas e as profilaxias dessa doença. Logo, em uma perspectiva de educação em saúde, o professor irá priorizar o entendimento da forma como a doença pode afetar os seres humanos, como ela é adquirida, o que pode ser feito para evitar o contágio, como trabalhar com a população atingida por esse mal, dentre outros assuntos que não ficarão restritos a definições.

Educação para a saúde é um conceito que encontramos na obra de Fonseca (1994, p. 27), e emprega-se como sinônimo de ensino de saúde, sendo compreendido como a "transmissão de conhecimentos e informações, mas principalmente no desenvolvimento de hábitos, atitudes, habilidades e comportamentos que ajudem na 
promoção, proteção, conservação, recuperação e reabilitação da saúde". Conceição (1994) menciona que, em seus primórdios, a educação para a saúde era denominada educação sanitária ${ }^{2}$. Esse autor também utiliza essa denotação como equivalente ao ensino de saúde, e enfatiza seu objetivo principal como a mudança comportamental dos sujeitos. Deste modo, educação para saúde é outra conotação que foge dos parâmetros adotados por nós, neste trabalho. Pela definição tem-se claramente que tal expressão visa como principal objetivo desenvolver hábitos nos indivíduos, e não apresenta nenhum caráter pedagógico intencional.

Por fim, cabe-nos apresentar as diferenças contidas na denominação promoção da saúde. Rey (2011) nos apresenta que o termo "promoção de saúde" formalizou-se na década de 70, e inicialmente foi concebido por uma perspectiva behaviorista de transformação de comportamentos individuais não saudáveis, como meio para evitar doenças. Candeias (1997, p. 210), de uma maneira geral, expressa que promoção da saúde é "uma combinação de apoios educacionais e ambientais que visam a atingir ações e condições de vida conducentes à saúde". Schall e Struchiner (1999, p. 4) concebem que

\begin{abstract}
ao conceito de educação em saúde se sobrepõe o conceito de promoção da saúde, como uma definição mais ampla de um processo que abrange a participação de toda a população no contexto de sua vida cotidiana e não apenas das pessoas sob risco de adoecer. Essa noção está baseada em um conceito de saúde ampliado, considerado como um estado positivo e dinâmico de busca de bem-estar, que integra os aspectos físico e mental (ausência de doença), ambiental (ajustamento ao ambiente), pessoal/emocional (auto-realização pessoal e afetiva) e sócio-ecológico (comprometimento com a igualdade social e com a preservação da natureza).
\end{abstract}

A partir desta última concepção, podemos analisar que a promoção da saúde tem um enfoque mais amplo, e que a educação em saúde é uma parte integrante das ações de promoção da saúde. Nessa mesma linha de pensamento, Buss (1999) apresenta a promoção da saúde como sendo articuladora dos saberes técnicos e populares, a qual possibilita a mobilização de recursos institucionais e comunitários, públicos e privados, de diversos setores, para o enfrentamento e a resolução dos problemas de saúde e seus

\footnotetext{
${ }^{2}$ Em relação à educação sanitária, Cardoso de Melo (1981), mostra-nos que o termo foi proposto em 1919, durante uma conferência internacional sobre a criança, realizada nos Estados Unidos. Tal data marca a criação da área educação sanitária. Concebendo-se a perspectiva da educação sanitária, as noções de higiene começaram a ser propostas "através de medidas preventivas, imunizações e cuidados individuais na prevenção, para o que era mister educar os indivíduos, principalmente as crianças. [...] A educação sanitária começa a fazer parte de currículos e programas de ensino" (CARDOSO DE MELO, 1981, p. 34).
} 
determinantes. Apoiados nessas definições, proferimos uma diferenciação mais evidente entre essas duas terminologias, na qual concebemos a promoção da saúde como consistindo em algo mais direcionado para a aquisição de objetivos comportamentais, diferentemente da educação em saúde que possui um caráter primordialmente educativo.

Rodrigues (2006) não diferencia as expressões educação para a saúde e promoção da saúde, utilizando ambas para se referir a atividades que tenham o objetivo de capacitar as pessoas para tomar decisões, mudar de atitudes, corrigir comportamentos, potenciar práticas adequadas e favorecer o empowerment. Novamente podemos observar que tanto a educação para a saúde, como a promoção da saúde reafirmam seu forte caráter comportamental, que destoa da nossa lógica de educação em saúde empregada na condução de nossas pesquisas.

\section{A educação em saúde na escola brasileira}

Ao compreendermos o caráter multifacetado da educação em saúde e ao diferenciarmos sua concepção de saúde escolar, saúde do escolar, ensino de saúde, educação para a saúde e promoção da saúde, podemos adentrar o espaço escolar e iniciar a traçar pressupostos sobre educação em saúde na escola. Para tal, retomamos nosso entendimento de educação em saúde, o qual consiste em atividades que compõem o currículo escolar, que apresentam uma intenção de caráter pedagógico, a qual contenha relação com o ensino e aprendizagem de assuntos ou temas correlatos com a saúde. Assim nos perguntamos: Qual a gênese da obrigatoriedade da discussão das questões de saúde na escola no Brasil?

Mohr e Schall (1992) nos apresentam que a implementação da saúde nas escolas tornou-se obrigatória através do Artigo 7, da Lei 5.692 de $1971^{3}$. Por essa lei, as ações de saúde eram estabelecidas por meio dos programas de saúde nas escolas de $1^{\circ}$ e $2^{\circ}$ graus, com o objetivo de estimular o conhecimento e a prática da saúde básica e da higiene. Ressaltamos que os programas de saúde tinham um forte caráter higienista, o qual destoa das intencionalidades da educação em saúde.

Um ano após a promulgação da Lei 5.692/71, Marcondes, em 1972, apresenta os objetivos de educação em saúde na escola, os quais na sua visão consistiam em:

\footnotetext{
${ }^{3}$ Art. $7^{\circ}$ : Será obrigatória a inclusão de Educação Moral e Cívica, Educação Física, Educação Artística e Programas de Saúde nos currículos plenos dos estabelecimentos de $1^{\circ}$ e $2^{\circ}$ graus (BRASIL, 1971).
} 
a. Contribuir para a proteção e promoção da saúde do escolar, proporcionando-lhe um ambiente físico e emocional adequado ao seu crescimento e desenvolvimento, ajudando-o a compreender a importância dos exames de saúde periódicos, estimulando-o a utilizar os recursos de saúde da comunidade, correndo para a prevenção e controle das doenças transmissíveis.

b. Desenvolver um currículo orientado no sentido de atender as necessidades do escolar, proporcionando-lhes experiências de aprendizagem que o habilitem a aplicar as descobertas científicas em benefício de sua saúde. c. Levar o escolar a compreender a necessidade da sua participação para o equacionamento dos problemas de saúde pessoais, de sua família e de sua comunidade (MARCONDES, 1972, p. 91).

Podemos observar que os objetivos estabelecidos por esse autor tentam avançar em relação ao que havia sido promulgado na Lei 5.692/71, mas ainda continua muito centrado na questão das doenças e problemas de saúde. Indo mais adiante no artigo desse autor, podemos ver a estruturação do programa de educação em saúde na escola que ele apresenta. Esse programa dividia-se em quatro áreas: ambiente da escola, serviços de saúde, ensino de saúde e relações lar-escola-comunidade. Por meio desta divisão, complementamos nossa constatação, de que tal estrutura está distante do pressuposto de educação em saúde, pois, até mesmo a área que se refere ao ensino de saúde era focada nas questões de: higiene; nutrição; saúde oral; etiologia, transmissão e profilaxia das doenças transmissíveis; entre outras desse gênero, as quais não contribuem para a potencialização da educação em saúde. Deste modo, podemos inferir que, desde os primórdios das discussões de saúde no espaço escolar, estas estão centradas na saúde escolar e nas campanhas de saúde pública, as quais possuem um acentuado caráter assistencialista e ausência de pressupostos pedagógicos.

Em 1996, a Lei 5.692 foi revogada pela promulgação da Lei de Diretrizes e Bases da Educação (LDB) (BRASIL, 1996). Nesta lei que veio substituir a anterior, os programas de saúde foram suprimidos, e a única alusão à saúde emerge no momento em que se faz referência ao dever do Estado com educação escolar pública, o qual será efetivado mediante a garantia de atendimento ao educando, no Ensino Fundamental público, por meio de programas suplementares de material didático-escolar, transporte, alimentação e assistência à saúde (BRASIL, 1996). Desta maneira, nenhuma questão pedagógica referente ao ensino de questões de saúde está presente nesta lei.

De maneira simultânea, a promulgação da LDB, de 1996, o Ministério da Educação (MEC) inicia, em 1995, a formulação de novos Parâmetros Curriculares Nacionais (PCN) para o ensino. Nesta reforma, além de instituir os novos parâmetros de 
cada disciplina (Língua Portuguesa, Matemática, Ciências Naturais, História e Geografia, Arte e Educação Física), também emerge a proposta de implementação dos temas transversais, os quais contemplam as questões da ética, da pluralidade cultural, do meio ambiente, da saúde e da orientação sexual (BRASIL, 1997a). Tais temas, segundo Arteaga Rodríguez et al (2007), são estabelecidos mediante as mudanças da estrutura curricular clássica para conteúdos mais amplos, as quais estão dadas pela necessidade do momento histórico, no qual a concepção holística e a globalização do mundo impõem novas metas ao sistema educacional. Bolívar (1998) nos provoca ao dizer que, a partir de temas denominados transversais, temos de educar para a vida, e que a questão da transversalidade, longe de introduzir um conjunto de temas no currículo estabelecido, necessita ser o compromisso colegiado de uma escola, compartilhado pela comunidade, para oferecer um ensino aberto à vida.

Por meio dos $\mathrm{PCN}^{4}$, podemos ver que a saúde se apresenta de forma explícita em dois volumes. Primeiramente ela emerge no PCN de Ciências Naturais (BRASIL, 1997b), em um bloco temático intitulado ser humano e saúde e, no outro, integra o tema transversal saúde (BRASIL, 1997c). Ao analisar de uma maneira atenta o PCN de Ciências Naturais, podemos perceber que ele apresenta o equilíbrio dinâmico, característico do corpo humano, como sendo o estado de saúde do indivíduo, e nos mostra que

o estado de saúde é condicionado por fatores de várias ordens: físicos, psíquicos e sociais. A falta de um ou mais desses condicionantes da saúde pode ferir o equilíbrio e, como consequência, o corpo adoece. Trabalhando com a perspectiva do corpo como um todo integrado, a doença passa a ser compreendida como um estado de desequilíbrio do corpo e não de alguma de suas partes. Uma disfunção de qualquer aparelho ou sistema representa um problema do corpo todo e não apenas daquele aparelho ou sistema (BRASIL, 1997b, p. 51).

Esta proposição vai ao encontro da concepção de saúde da OMS, e também apresenta uma ideia de corpo humano integrado e não fragmentado (como é visto na maioria das vezes). Nesta perspectiva, um desequilíbrio em qualquer órgão afeta todo o organismo. A partir desta percepção, ao longo do documento vão sendo discorridas sugestões de como trabalhar o corpo humano em sala de aula, bem como as questões que visem o desenvolvimento de uma consciência do indivíduo sobre o cuidado com sua saúde. Isto pode ser percebido quando aponta que "é papel da escola subsidiar os

\footnotetext{
${ }^{4}$ Parâmetros Curriculares Nacionais destinados aos anos iniciais do Ensino Fundamental.
} 
alunos com conhecimentos e capacidades que os tornem aptos a discriminar informações, identificar valores agregados a essas informações e realizar escolhas [que favoreçam a saúde]" (BRASIL, 1997b, p. 53).

Mesmo apresentando-se dentro do PCN de Ciências Naturais, a questão da saúde não pode ser pensada como campo disciplinar, sendo elencada pelo MEC como um tema transversal. Mohr (2002, p. 81) constatou que é necessária, à educação em saúde, "ultrapassar o campo disciplinar das ciências naturais e que, dentro desta disciplina, a tríade tradicional corpo humano/higiene/nutrição seja superada". Para essa mesma autora, o erro de muitos estudiosos, que discutem as questões de educação em saúde e sua relação com os componentes curriculares, está

precisamente em tentar encontrar temas de saúde na ciência ou em qualquer outra área disciplinar do conhecimento. É um erro epistemológico querer abarcar o complexo fenômeno da saúde através de qualquer área disciplinar. Ao contrário, o que existe são aspectos de biologia, de sociologia, de economia, de geografia, de matemática presentes em determinado problema de saúde que se tome para análise (MOHR, 2002, p. 91).

Alinhados com este pensamento, o MEC apresenta que os PCN dos temas transversais foram implementados pelo fato de que "algumas propostas indicaram a necessidade do tratamento transversal de temáticas sociais na escola, como forma de contemplá-las na sua complexidade, sem restringi-las à abordagem de uma única área" (BRASIL, 1997a, p. 64), e a saúde foi uma destas temáticas.

$\mathrm{Na}$ apresentação do PCN de saúde menciona-se que:

O ensino de saúde tem sido um desafio para a educação, no que se refere à possibilidade de garantir uma aprendizagem efetiva e transformadora de atitudes e hábitos de vida. As experiências mostram que transmitir informações a respeito do funcionamento do corpo $e$ descrição das características das doenças, bem como um elenco de hábitos de higiene, não é suficiente para que os alunos desenvolvam atitudes de vida saudável. $E$ preciso educar para a saúde levando em conta todos os aspectos envolvidos na formação de hábitos e atitudes que acontecem no dia-a-dia da escola. Por esta razão, a educação para a Saúde será tratada como tema transversal, permeando todas as áreas que compõem o currículo escolar. O documento de Saúde situa a realidade brasileira, indicando possibilidades de ação e transformação dos atuais padrões existentes na área da saúde (BRASIL, 1997 c, p. 85, grifos nosso).

Deste pressuposto é importante destacarmos dois aspectos: primeiro salienta-se que transmitir informações, bem como realizar descrições não é suficiente para que os alunos desenvolvam atitudes saudáveis. Por outro lado, o PCN concebe a educação em 
saúde como consistindo na formação de hábitos e atitudes que ocorrem na escola. Com esta concepção já antevemos que as orientações presentes neste documento, fogem da lógica traçada nesta pesquisa, pois, em nosso entendimento, a educação em saúde vai além da simples aquisição de hábitos e atitudes.

Outro aspecto que nos chama a atenção no PCN de saúde (BRASIL, 1997c) consiste quando é realizado o seguinte questionamento: Ensinar saúde ou educar para a saúde? Neste momento é exposto que, referente ao ensinar saúde, o foco incide em tratar de conceitos que fundamentaram a proposta clássica de inserção dos programas de saúde, restritos à disciplina de Ciências Naturais. Desta maneira, este documento vislumbra quão insuficiente é o ensino de saúde como forma de garantir uma abordagem de conteúdos relativos aos procedimentos e atitudes necessários à promoção da saúde. Assim nos é apresentado o seguinte:

\begin{abstract}
Quando inicia sua vida escolar, a criança traz consigo a valoração de comportamentos favoráveis ou desfavoráveis à saúde oriundos da família e outros grupos de relação mais direta. Durante a infância e a adolescência, épocas decisivas na construção de condutas, a escola passa a assumir papel destacado devido à sua função social e por sua potencialidade para o desenvolvimento de um trabalho sistematizado e contínuo. Deve, por isso, assumir explicitamente a responsabilidade pela educação para a saúde, já que a conformação de atitudes estará fortemente associada a valores que o professor e toda a comunidade escolar transmitirão inevitavelmente aos alunos durante o convívio escolar. [...] Isso não quer dizer que as informações e a possibilidade de compreender a problemática que envolve as questões de saúde não tenham importância ou que não devam estar presentes no processo de ensinar e aprender para a saúde, mas sim que a educação para a Saúde só será efetivamente contemplada se puder mobilizar as necessárias mudanças na busca de uma vida saudável. Para isso, os valores e a aquisição de hábitos e atitudes constituem as dimensões mais importantes (BRASIL, 1997c, p. 9798, grifos nosso).
\end{abstract}

Podemos ver que o documento expõe as limitações de um ensino de saúde, mas apresenta problemas no seu entendimento da educação em saúde, visto que deixa claro que as dimensões mais importantes de tal prática residem em valores e aquisição de hábitos e atitudes nos sujeitos. Por uma interpretação crítica sobre os PCN, Mohr (2002) questiona: se a função da escola é principalmente o de desenvolver valores, atitudes e comportamentos, estes objetivos podem ser adquiridos na vivência empírica, sendo obtidos simplesmente pelo bom exemplo de ambientes e pessoas que praticam a vida saudável. Desta maneira, por tal concepção é retirado o sentido e a função "da escola como locus de desenvolvimento e a apropriação do conhecimento pelos indivíduos" (MOHR, 2002, p. 67). Essa autora é ainda mais enfática ao apresentar que "a partir do 
momento em que a escola renuncia a um de seus objetivos principais (aquele de desenvolver nos alunos conceitos, raciocínio e crítica), não há mais necessidade desta instituição na sociedade" (MOHR, 2009, p. 123).

Após termos apresentado o início da obrigatoriedade das questões de saúde na escola por meio dos programas de saúde, bem como o avanço e limitações adquiridas com a publicação dos PCN, outra política nacional, mais recente, foi escolhida para ser abordada neste artigo. Esta consiste no programa saúde na escola - PSE, instituído pelo Decreto 6.286, de 5 de dezembro de 2007. No primeiro artigo deste decreto, consta a finalidade deste programa, a qual consiste em "contribuir para a formação integral dos estudantes da rede pública de Educação Básica por meio de ações de prevenção, promoção e atenção à saúde" (BRASIL, 2007).

O programa saúde na escola é instituído no âmbito do Ministério da Educação e da Saúde, assim, segundo Figueiredo et al (2010, p. 401),

\footnotetext{
as ações em saúde previstas no âmbito do PSE, a serem desenvolvidas em articulação com a Saúde e a Educação, deverão considerar a integralidade dos educandos, o que significa garantir a cada um deles o direito à avaliação clínica, oftalmológica, auditiva, psicossocial, saúde e higiene bucal, avaliação nutricional, promoção de alimentação saudável, bem como acesso a ações educativas que lhes garantam educação permanente em saúde -, através de uma cultura da prevenção no âmbito escolar (grifos nosso).
}

Analisando as ações propostas no PSE, podemos ver que as ações de caráter assistencialistas estão expressas como forma de garantir os direitos dos educandos, mas, ao lado destas práticas, tal programa almeja também o "acesso a ações educativas que lhes garantam educação permanente em saúde". Acreditamos ser o acesso a essas ações educativas o grande avanço deste programa, pois, desta forma, não estarão dissociados os objetivos pedagógicos que caracterizam as práticas de educação em saúde.

\section{Muitas possibilidades e algumas barreiras da educação em saúde na escola}

Após analisarmos como se inseriram as questões de saúde na escola, podemos pensar como a educação em saúde pode ser viabilizada no espaço escolar. Mohr e Schall (1992) expressam que são infinitas as possibilidades para se desenvolver atividades de educação em saúde, mas salientam que estas devem ser estruturadas de acordo com cada situação, pois: 
As peculiaridades cultural e ambiental de cada comunidade exigem que todas as ações partam de tal especificidade e que a levem em consideração estrita. Campanhas de caráter nacional que desconsideram as particularidades regionais de nomenclatura atribuídas a vetores de doenças, por exemplo, ou ainda os hábitos culturais e sociais distintos de populações geograficamente próximas estão fadadas ao insucesso. Da mesma forma, atividades desenvolvidas na escola, que têm por ponto de partida situações alheias à realidade vivida pelos seus alunos, desperdiçam tempo e oportunidades valiosas. $\mathrm{O}$ mesmo ocorre quando se ignora o conhecimento popular acerca de determinada situação, desvalorizando-o e inferiorizando-o, ao invés de trabalhar junto e a partir dele (MOHR; SCHALL, 1992, p. 201).

Essas autoras salientam que, mesmo tendo infinitas possibilidades para ser trabalhada na escola, a educação em saúde precisa estar vinculada com os anseios da comunidade onde está inserida, bem como deve ser levado em conta o conhecimento popular dos sujeitos. Mas, mesmo tendo variadas possibilidades para promover a educação em saúde, algumas barreiras são encontradas.

O primeiro fator limitante, acreditamos, é o fato de a formação do professor nos domínios da educação em saúde ser deficitária. No estudo de Fernandes et al (2005), questionou-se sobre as dificuldades encontradas para trabalhar o tema saúde dentro do ambiente escolar, e a questão referente à falta de capacitação docente obteve destaque. Relacionando as dificuldades decorrentes da formação dos professores para trabalhar com a educação em saúde, cabe apresentar o resultado de dois estudos no campo de investigações de currículos universitários. Zancul e Gomes (2011), analisando o currículo do Curso de Licenciatura em Ciências Biológicas, da Universidade de Brasília $(\mathrm{UnB})$, constataram que nenhuma disciplina trata realmente das questões de educação em saúde. Assim, os futuros professores de Ciências e Biologia acabam não tendo esse tipo de discussão em sua formação, o que acabará por dificultar sua atuação docente. Leonello e L'Abbate (2006), na análise realizada sobre o currículo do Curso de Pedagogia, da Universidade Estadual de Campinas (Unicamp), constataram que duas das 73 disciplinas analisadas trabalham a educação em saúde na escola de modo implícito, sendo elas: "Fundamentos do Ensino de Ciências" e "Fundamentos da Educação Infantil”. Nesta investigação podemos ver que, mesmo sendo consideradas pelas autoras do estudo como disciplinas que contemplam as questões de saúde, ambas apresentam de forma subjetiva a abordagem das questões de educação em saúde, pois nenhuma menção é feita explicitamente aos termos "saúde" ou "educação em saúde". Com esses trabalhos, podemos constatar que a construção de conhecimentos acerca das questões de educação em saúde não é proporcionada aos licenciados em Pedagogia e Ciências Biológicas em seus cursos de formação. Essa forma de estruturação curricular, 
a qual negligencia a abordagem da educação em saúde, pode ser a origem da formação deficitária de professores para trabalhar com esta temática na escola.

Para superar essas dificuldades resultantes da formação inicial de professores para abordar a educação em saúde, Mohr e Schall (1992, p. 201) propõe que

\begin{abstract}
é necessário, também, realizar cursos de atualização para professores que aperfeiçoem sua eficiência pedagógica e ampliem sua visão da questão da saúde nos seus múltiplos aspectos. Isto é essencial para o encaminhamento de uma ação participativa e criadora dos alunos. É importante estimular os professores a planejarem e executarem projetos em conjunto com seus alunos, investigando algum problema de saúde relevante para a região da escola e propondo ações e alternativas de solução.
\end{abstract}

A alternativa de cursos de atualização para os professores aperfeiçoarem seu fazer docente é uma opção viável para a minimização dessa dificuldade. Paralelo à barreira decorrente da formação dos professores, emergem outras como: falta de material didático, falta de apoio do ambiente familiar e escassez de recursos humanos (FERNANDES et al, 2005).

Mesmo com tais barreiras para promover a educação em saúde no espaço escolar, vários autores apresentam a importância desta prática na escola. Marcondes (1972), utilizando a concepção de educação para saúde, nos diz que, na escola, o importante consiste na formação de atitudes e valores que levam o escolar ao comportamento inteligente, em benefício de sua saúde e da saúde dos outros. Mohr (2002, p. 70) acredita que à escola "cabe instrumentalizar intelectualmente, a longo prazo e em profundidade, os alunos para que analisem criticamente a realidade e possam fazer, no campo da saúde, escolhas autônomas e informadas”. Arteaga Rodríguez et al (2007) concebem que as pessoas devam possuir instrução sobre saúde a qual lhes permita aprender as medidas indicadas e tomar consciência das mesmas, e acredita que a escola configura-se como um local importante para isso. Para Zômpero et al (2010, p. 105), "a escola é o local apropriado para a aprendizagem de saúde, primeiro por reunir crianças em faixas etárias propícias à adoção de medidas educativas e preventivas, mas também pela presença do professor no processo de mediação dos conhecimentos". Zancul e Gomes (2011) também consideram as escolas como sendo locais privilegiados para trabalhar atividades de educação em saúde.

Constatando a potencialidade da escola como local para promover a educação em saúde, devemos concordar com Conceição (1994), quando menciona que as ações de saúde devem englobar atividades de educação para a saúde, não ficando limitadas 
àquelas praticadas concomitantemente às atividades assistenciais. No estudo de Fernandes et al (2005), foi diagnosticado que as escolas não se sentem responsáveis pela prática da saúde em seus ambientes e geralmente reproduzem essas atividades de caráter assistencialista, priorizando o indivíduo e a doença, em detrimento da coletividade e da prevenção.

Uma discussão que ganha força no campo da educação em saúde gira em torno de qual profissional deve trabalhar com as questões de saúde na escola? Os professores, ou os profissionais da saúde? Arteaga Rodríguez et al (2007) constataram que é evidente a separação entre educação e saúde, e uma articulação se faz necessária, visto que as escolas necessitam incorporar temas referentes à saúde, visando o bem-estar dos seus alunos. Esses autores argumentam que a educação e a saúde são necessidades sociais que devem ser garantidas pelas instituições, e diagnosticam a importância de a escola atuar como promotora da saúde, mas sabem da dificuldade e da separação existente entre as questões de saúde e de educação.

O "conflito" existente entre os profissionais da saúde e da educação, no que se refere ao tratamento das questões, é evidente, e Silva (1994, p. 22) nos mostra que "a atenção à Educação e à Saúde da criança e do adolescente certamente é tarefa para a qual devem confluir educadores e trabalhadores em saúde, com competências específicas". Para solucionar esse embate entre profissionais da saúde e professores, recorremos a Mohr (2002, p. 38) a qual compreende que a educação em saúde,

como parte do currículo escolar, pode ser desenvolvida por professores, ou outros profissionais da educação [...]. Pode, também, incluir profissionais de áreas distintas à da educacional, que estejam articulados com a proposta curricular. Assim, a educação em saúde pode estar presente na forma de atividade planejada pela escola, na qual um grupo de profissionais da enfermagem e do corpo de bombeiros incluem-se, sob a coordenação do professor, de parte de um projeto de capacitação dos alunos para administrar os primeiros socorros (grifos nosso).

Mas esta autora nos mostra também que, muitas vezes, as iniciativas consideradas de educação em saúde, oferecidas às escolas por instituições da área da saúde ou afins, refletem uma concepção de que se faz educação em saúde transmitindo informações (MOHR, 2002).

Fernandes et al (2005, p. 290), no que se refere à relação professores/profissionais da saúde, constata que 
a questão da saúde escolar precisa ser mais bem trabalhada com os docentes - os quais ainda não concebem muito bem o real significado dessa prática - e com toda a escola. É necessária a realização de capacitações e treinamentos para os profissionais do campo educacional, além de um maior envolvimento dos profissionais da área da saúde. Estes últimos devem dar uma maior contribuição para um bom desenvolvimento das ações de saúde no ambiente escolar, em especial fornecendo um maior suporte aos educadores (grifos nosso).

Esse apontamento revela que os docentes têm dificuldade em entender aspectos sobre a educação em saúde e também expressa a maior necessidade de engajamento dos profissionais da área da saúde no espaço escolar. Podemos constatar, desse modo, que os profissionais da saúde podem proporcionar um suporte aos professores; podem também realizar ações na escola, mas essas nunca sem o acompanhamento do docente, pois será o educador que poderá desvencilhar-se dessa concepção de que as questões de saúde possam ser transmitidas aos alunos.

Retomando nossa concepção inicial de educação em saúde como consistindo nas atividades que compõem o currículo escolar, que apresentam uma intenção de caráter pedagógico, a qual contenha relação com o ensino e a aprendizagem de assuntos ou temas correlatos com a saúde, fica evidente que quem proporcionará esse caráter pedagógico será o professor, e não os demais profissionais da saúde. Deste modo, os professores devem começar a se autorizar e se legitimar como educadores em saúde.

\section{Considerações finais}

Podemos evidenciar que por ter um caráter multifacetado, o conceito de educação em saúde necessita ser problematizado. É importante termos clareza dessa definição para buscarmos compreensões dos fenômenos e problemas desse campo de estudo. Evidenciamos também, que desde que a saúde foi introduzida nas escolas, é marcante a característica que prima pela mudança comportamental. Desde os programas de saúde, passando pela promulgação dos PCN e mais recentemente pelo PSE, é possível perceber as marcas dessa ideia de educação em saúde atrelada a mudança de comportamento. As implicações de um trabalho da educação em saúde na escola, que considere unicamente a mudança comportamental do sujeito, podem ser insuficientes, pois este não irá entender os reais motivos de se primar por uma boa saúde.

Analisando as potencialidades e as barreiras para a concretização da educação em saúde nas práticas de ensino escolares, foi possível evidenciar a importância do trabalho com a temática, pelo significado que exprimem aos alunos. Por outro lado, 
podemos ver que algumas barreiras acabam por limitar o trabalho docente. Apontamos como algum desses fatores limitantes a formação dos professores para trabalhar com a questão e a falta de diálogo com os profissionais da saúde. Acreditamos que para superar esses empecilhos seja necessários cursos de aperfeiçoamento para os professores, em relação à temática da educação em saúde, bem como um trabalho mais sistematizado entre educadores e profissionais da área da saúde.

\section{Referências}

ARTEAGA RODRÍGUEZ, Carlos; KOLLING, Marcelo Garcia; MESQUIDA, Peri. Educação e saúde: um binômio que merece ser resgatado. Rev. bras. educ. med. [online], Rio de Janeiro, v. 31, n. 1, p. 60-66, abr. 2007. Disponível em: <http://dx.doi.org/10.1590/S0100-55022007000100009>. Acesso em: 10 abr. 2011.

BOLÍVAR, Antonio. Prefácio. In: YUS, Rafael. Temas transversais: em busca de uma nova escola. Porto Alegre: Artmed, 1998. p. v-xi.

BRASIL. Lei ${ }^{\circ} 5692$, de 11 de agosto de 1971. Estabelece as diretrizes e bases para o ensino de $1^{\circ}$ e $2^{\circ}$ graus. Brasília, DF, 1971.

. Lei $\mathrm{n}^{\circ} 9394$, de 20 de dezembro de 1996. Estabelece as diretrizes e bases da educação nacional. Brasília, DF, 1996.

. Secretaria de Educação Fundamental. Introdução aos Parâmetros

Curriculares Nacionais: primeiro e segundo ciclos. Brasília: MEC/SEF, 1997a.

. Secretaria de Educação Fundamental. Parâmetros Curriculares Nacionais: primeiro e segundo ciclos - ciências naturais. Brasília: MEC/SEF, 1997b.

. Secretaria de Educação Fundamental. Parâmetros curriculares nacionais:

primeiro e segundo ciclos - meio ambiente, saúde. Brasília: MEC/SEF, 1997c.

. Decreto $\mathrm{n}^{\circ} \mathbf{6 2 8 6}$, de 5 de dezembro de 2007. Institui o Programa Saúde na Escola - PSE. Brasília, DF, 2007.

BUSS, Paulo Marchiori. Promoção e educação em saúde no âmbito da Escola de Governo em Saúde da Escola Nacional de Saúde Pública. Cad. Saúde Pública [online], Rio de Janeiro, v. 15, sup. 2, p. 177-185, 1999. Disponível em: <http://dx.doi.org/10.1590/S0102-311X1999000600018>. Acesso em: 23 ago. 2011.

CANDEIAS, Nelly Martins Ferreira. Conceitos de educação e de promoção em saúde: mudanças individuais e mudanças organizacionais. Rev. Saúde Pública [online], São Paulo, v. 31, n. 2, p. 209-13, abr. 1997. Disponível em: <http://dx.doi.org/10.1590/S0034-89101997000200016>. Acesso em: 14 jul. 2011.

CARDOSO DE MELO, Joaquim Alberto. Educação sanitária: uma visão crítica. In: CANESQUI, Ana Maria; CAMARGO, Elizabeth Silvares P. de; BARROS, Maulisa 
Berti de. Educação e saúde. São Paulo: Cortez, 1981. P. 28-43 (Cadernos do CEDES, $4)$.

CONCEIÇÃO, José Augusto Nigro. Saúde escolar: a criança, a vida e a escola. São Paulo: Sarvier, 1994.

FERNANDES, Marcos Henrique; ROCHA, Vera Maria; SOUZA, Djanira Brasilino de. A concepção sobre saúde do escolar entre professores do ensino fundamental $\left(1^{\mathrm{a}}\right.$ a $4^{\mathrm{a}}$ séries). Hist. cienc. saúde-Manguinhos [online], Rio de Janeiro, v.12, n.2, p. 283-291, maio/ago. 2005. Disponível em: < http://dx.doi.org/10.1590/S0104-

59702005000200004>. Acesso em: 13 abr. 2011.

FIGUEIREDO, Túlio Alberto Martins de; MACHADO, Vera Lúcia Taqueti; ABREU, Margaret Mirian Scherrer de. A saúde na escola: um breve resgate histórico. Ciênc. saúde coletiva [online], Rio de Janeiro, v.15, n.2, p. 397-402, mar. 2010. Disponível em: <http://dx.doi.org/10.1590/S1413-81232010000200015>. Acesso em: 13 maio 2011.

FONSECA, João Pedro da. Aluno, paciente, cidadão: a saúde escolar em questão. CONCEIÇÃO, José Augusto Nigro (Org.). Saúde escolar: a criança, a vida e a escola. São Paulo: Sarvier, 1994. p. 23-32.

LEONELLO, Valéria Marli; L'ABBADE, Solange. Educação em Saúde na escola: uma abordagem do currículo e da percepção de alunos de graduação em Pedagogia. Interface - Comunic., Saúde, Educ. [online], Botucatu, v. 10, n. 19, p.149-166, jan./jun. 2006. Disponível em: < http://dx.doi.org/10.1590/S1414-32832006000100011>. Acesso em: 11 maio 2011.

LIMA, Gérson Zanetta de. Saúde escolar e educação. São Paulo: Cortez, 1985.

MARCONDES, Ruth Sandoval. Educação em saúde na escola. Rev. Saúde Pública. [online], São Paulo, v. 6, n. 1, p. 89-96, mar. 1972. Disponível em: <http://dx.doi.org/10.1590/S0034-89101972000100010>. Acesso em: 27 abr. 2011.

MOHR, Adriana; SCHALL, Virgínia T. Rumos da educação em saúde no Brasil e sua relação com a Educação Ambiental. Cad. Saúde Pública [online]. Rio de Janeiro. v. 8, n. 2, p. 199-203, abr./jun. 1992. Disponível em: < http://dx.doi.org/10.1590/S0102-311X1992000200012>. Acesso em: 29 jun. 2011.

MOHR, Adriana. A natureza da educação em saúde no ensino fundamental e os professores de ciências. Santa Catarina. 2002. Tese (Doutorado). Programa de PósGraduação em Educação, Centro de Ciências da Educação, Universidade Federal de Santa Catarina.

Ensino de Ciências e Biologia e educação em saúde: análise das proposições dos Parâmetros Curriculares Nacionais (Educação Fundamental). In: JOFILI, Zélia; ALMEIDA, Argus (Orgs.). Ensino de Biologia, meio ambiente e cidadania: olhares que se cruzam. Recife: Editora Universitária da UFRPE, 2009, v. 1, p. 119-128. 
OMS. Organização Mundial da Saúde. Constituição da Organização Mundial da Saúde. 1946. Disponível em: <http://www.fd.uc.pt/CI/CEE/OI/OMS/OMS.htm>. Acesso em: 23 abr. 2012.

REY, Fernando González. Subjetividade e saúde: superando a clínica da patologia. São Paulo: Cortez, 2011.

RODRIGUES, Manuel Alves. Perspectiva interdisciplinar na formação de "educadores de saúde". In: HAMIDO, Gracinda et al. (Orgs.). Transversalidade em educação e em saúde. Porto: Porto Editora, 2006. p. 133-138.

SCHALL, Virgínia T.; STRUCHINER, Miriam. Educação em saúde: novas perspectivas. Cad. Saúde Pública [online], Rio de Janeiro, v. 15, suppl. 2, p. S4-S6, 1999. Disponível em: <http://dx.doi.org/10.1590/S0102-311X1999000600001〉. Acesso em: 19 maio 2011.

SILVA, Jair Militão da. A criança, a educação e a saúde: a educação escolar. In: CONCEIÇÃO, José Augusto Nigro (Org.). Saúde escolar: a criança, a vida e a escola. São Paulo: Sarvier, 1994. p. 19-22.

SUCUPIRA, Ana Cecília Silveira Lins; ZUCCOLOTTO, Sandra Maria Callioli. Atenção integral à saúde do escolar. In: CONCEIÇÃO, José Augusto Nigro (Org.). Saúde escolar: a criança, a vida e a escola. São Paulo: Sarvier, 1994. p. 204-214.

ZANCUL, Mariana de Senzi; GOMES, Paulo Henrique Mendes. A formação de licenciandos em Ciências Biológicas para trabalhar temas de Educação em Saúde na Escola. REMPEC - Ensino, Saúde e Ambiente [online], Niterói, v.4 n. 1, p. 49-61, abr. 2011. Disponível em: <http://www.ensinosaudeambiente.com.br/edicoes/volume4/artigo5MarianaZancul.pdf> . Acesso em: 12 set. 2011.

ZÔMPERO, Andréia de Freitas; LABURÚ, Carlos Eduardo; PASSOS, Adriana Quimentão; GRACIANO, Nathalia. Multimodos de representação em atividades sobre higiene para educação infantil. Experiências em Ensino de Ciências (UFRGS) [online], Porto Alegre, v. 5, n. 3, p. 103-114, 2010. Disponível em:

<http://if.ufmt.br/eenci/index.php?go=artigos\&idEdicao=26>. Acesso em: 4 maio 2011. 